\title{
Long-term outcomes of metacarpal fractures surgically treated using bioabsorbable plates: a retrospective study
}

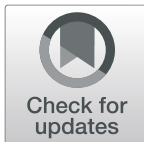

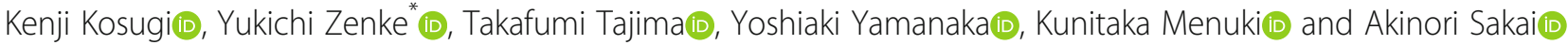

\begin{abstract}
Background: Implants made from bioabsorbable unsintered hydroxyapatite and poly-L-lactate composites (U-HA) PLLA) are widely used in the oral, maxillofacial, and orthopedic fields. This study assess the long-term (> 5 years) outcomes of patients with metacarpal fractures who were surgically treated using bioabsorbable plates and screws (Super-Fixsorb MX40 mesh; Teijin Medical Technology, Osaka, Japan).

Methods: A retrospective analysis of six patients with eight metacarpal fractures treated with bioabsorbable plates was done. All patients were followed for more than 5 years post-surgery. The clinical outcomes were evaluated using Q-DASH scores and the grip strength (GS): opposite side ratio. The resorption status of implants was assessed on plain computed tomography (CT) scans at final follow-up appointments.

Results: The mean age of the patients at the time of surgery was 29.5 years (16-54), and the median follow-up period was 81.8 months (68-101). All fractures united without displacement after an average of 3.5 months, and there were no implant specific complications associated with the use of absorbable plates. The mean grip strength ratio was $85.1 \%$ (56.8-104.5). The mean Q-DASH scores of 11.36 points (0-34.09) was good in all but two patients. We also observed that it took more than 8 years for the plates to be absorbed completely.

Conclusions: This study demonstrates that the process of bioabsorption in metacarpal fractures might be completed in about 8 years, and the absorption speeds were different inside and outside of the bone. The bioabsorbable plates are more cost-effective than metallic implants. The potential for bioabsorbable plates to be used in various clinical procedures is promising.
\end{abstract}

Keywords: Bioabsorbable plates, Metacarpal fractures, Long-term outcomes, U-HA/PLLA

\section{Background}

Metacarpal fractures are common, and most of them can be treated successfully without surgery [1]. However, open reduction and internal fixation is a common surgical treatment for unstable metacarpal fractures, and the use of metallic implants is considered the gold standard for operative treatment $[2,3]$. However, metallic implants may interfere with

\footnotetext{
* Correspondence: ukichi.drz@gmail.com

Department of Orthopaedic Surgery, University of Occupational and Environmental Health, 1-1 Iseigaoka, Yahatanishi-ku, Kitakyushu 807-8555, Japan
}

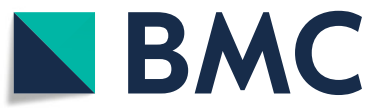

(c) The Author(s). 2020 Open Access This article is licensed under a Creative Commons Attribution 4.0 International License, which permits use, sharing, adaptation, distribution and reproduction in any medium or format, as long as you give appropriate credit to the original author(s) and the source, provide a link to the Creative Commons licence, and indicate if changes were made. The images or other third party material in this article are included in the article's Creative Commons licence, unless indicated otherwise in a credit line to the material. If material is not included in the article's Creative Commons licence and your intended use is not permitted by statutory regulation or exceeds the permitted use, you will need to obtain permission directly from the copyright holder. To view a copy of this licence, visit http://creativecommons.org/licenses/by/4.0/. The Creative Commons Public Domain Dedication waiver (http://creativecommons.org/publicdomain/zero/1.0/) applies to the data made available in this article, unless otherwise stated in a credit line to the data.

extensor tendon gliding and induce metallosis and allergic reactions [4]. Surgical removal of the implant is frequently required to avoid complications; moreover, titanium plates and screws are often difficult to remove after extended periods $[5,6]$.

Unsintered hydroxyapatite and poly-L-lactate composites (u-HA/PLLA) are resorbable osteosynthetic bone fixation implants with osteoconductive properties that promote replacement with new bone [7]. u-HA/PLLA constructs are radiopaque and have biomechanical strength equal to or greater than that of titanium plates 
[8]. Therefore, u-HA/PLLA composites are widely used in oral and maxillofacial, and orthopedic fields, especially fractures of the upper extremities such as metacarpal fractures and distal radial intra-articular fractures [811]; however, in the treatment of unstable metacarpal fractures, most surgeons still use metal plates. Animal studies have shown that composite u-HA/PLLA rods can be completely replaced by new bone in the distal femoral condyle of rabbits within 7.3 years without producing adverse reactions [7]. Human studies in oral and maxillofacial fields have shown that surgically implanted $\mathrm{u}$-HA/PLLA composites were absorbed in 6 years [12]. However, reports have described late-onset, foreign body reactions such as infections and aseptic swelling [1315]. Regarding orthopedics, no previous report has detailed long-term clinical outcomes using u-HA/PLLA plates.

This study aims to evaluate the long-term ( $>5$ years) outcomes of surgically treated metacarpal fractures using bioabsorbable plates.

\section{Methods}

From September 2009 to January 2013, total 32 patients with unstable metacarpal fractures were treated at the study hospital using bioabsorbable plates (Super-Fixsorb MX40 mesh; Teijin Medical Technology, Osaka, Japan). Twenty-six patients finally obtained bone union and full of range of motion without pain, therefore, completed follow-up within 1 year. Six patients (four males and two females, eight fingers), with follow-up for more than 5 years, were included in this study.

\section{Surgical procedures}

All patients underwent similar surgeries. Patients were either administered general or regional anesthesia using Ropivacaine, and a curved, longitudinal skin incision was made on the dorsal part of the hand. Open reductions were performed, and fractures were temporarily fixed using Kirschner wires that were $1.0 \mathrm{~mm}$ in diameter. Bioabsorbable mesh sheets $(50 \mathrm{~mm} \times 50 \mathrm{~mm} \times 0.7 \mathrm{~mm}$, height $\times$ width $\times$ depth) were cut into the appropriate shape for fixation of the fracture, and the sheets were bent using a hot water bath $\left(68^{\circ} \mathrm{C}\right)$ to make a one-third or semi-tubular plate. After placing the sheets in a hot water bath for about $15 \mathrm{~min}$, they were designed to anatomically fit the curved surface of the fractured metacarpal. Plates were anatomically fitted to curved surfaces of metacarpal bones (Additional File 1), and each was fixed with either four or six bioabsorbable, 2.0-mm diameter cortical screws (Super-Fixsorb MX30; Teijin Medical Technology, Osaka, Japan). Each plate was covered with fascia from the interosseous muscle to avoid irritation of the extensor tendon.
Postoperatively, the wrist and metacarpophalangeal joints were immobilized with a splint until swelling and pain had sufficiently diminished, which typically took about 1 week. Active range of motion exercises were then initiated to the extent that the patients could tolerate.

Clinical outcomes were evaluated through the assessment of the active range of motion (ROM) of the wrist and forearm, grip strength ratio (percentage of the unaffected side), and Quick-Disabilities of the Arm, Shoulder, and Hand (Q-DASH) score [16]. Those who cannot grip completely were defined as having a limited ROM. We judged Q-DASH score of 0 points as good. Patients were evaluated at their final follow-up appointment. Bone union on plain radiograph and complications such as infection and persistent swelling were assessed on follow-up visits. Resorption status of plates and screws were also assessed at final follow-up visits on plain computed tomography (CT) scans. We defined that the plate was completely absorbed when the shape of the plate could not be traced by 3D-CT. The data were expressed with average and standard deviation or median and minimal-maximal value.

\section{Results}

The clinical results for all patients are summarized in Table 1 . The mean age of the patients at the time of surgery was 29.5 years (range, 16-54 years), and the mean follow-up period was 81.8 months (range, 68-101 months). All fractures were united without displacement after an average of 3.5 months, and there were no implant specific complications such as inflammation and persistent swelling reported. The mean grip strength ratio (\%) was $85.1 \pm 17.5$ (range, $56.8-104.5)$. The mean QDASH scores (points) was 11.36 (range, 0-34.09). The score was good for all but two cases. In cases in which these were poor, patients had limited ranges of motion and poor recovery of grip strength ratios. On studying persistence or resorption it was found that both plates and screws typically persist for more than 6 years postsurgery. In fact, remnants of plate were observable 7 years post-surgery. The plate was completely absorbed 8 years and 5 months post-surgery, however, only a small quantity of screws remained within the bone.

\section{Case presentation \\ Case 1}

A 16-year-old male presented with a transverse metacarpal fracture of the left little finger as a result of bruising while playing baseball. We treated it with a bioabsorbable plate made from a single mesh sheet. The plate was anatomically fitted to the curved surface of the fractured bone. At final follow-up visit, 5-years and 8-months post-surgery, the active ROM of his wrist and forearm 
Table 1 Assessment of clinical outcomes of all patients recorded during the final follow-up appointment

\begin{tabular}{|c|c|c|c|c|c|c|c|c|c|c|}
\hline Case & Sex & Age & Affected hand & Affected finger & Dominant hand & Bone union & $\mathrm{F} / \mathrm{u}$ & Limited ROM & G-S ratio & Q-DASH \\
\hline 1 & $M$ & 16 & Right & Little & Right & $2 M$ & $5 Y 8 M$ & No & 79.2 & 0 \\
\hline 2 & $\mathrm{~F}$ & 54 & Right & Ring & Right & $3 M$ & $6 Y 5 M$ & No & 104.5 & 0 \\
\hline 3 & M & 17 & Right & Ring & Right & $2 \mathrm{M}$ & $6 Y 7 M$ & No & 100.7 & 0 \\
\hline 4 & M & 18 & Left & Ring & Right & $3 \mathrm{M}$ & $6 Y 8 M$ & Yes & 78.5 & 34.09 \\
\hline 5 & F & 52 & Right & Little & Right & $3 M$ & $7 Y 2 M$ & No & 91.1 & 0 \\
\hline 6 & M & 20 & Right & $\begin{array}{l}\text { Middle } \\
\text { Ring } \\
\text { Little }\end{array}$ & Right & $8 M$ & $8 Y 5 \mathrm{M}$ & No & 56.8 & 34.09 \\
\hline Ave. & & $29.5 \pm 18.2$ & & & & $3.5 \mathrm{M}$ & $6 Y 9 M$ & & $85.1 \pm 17.5$ & $11.36 \pm 17.60$ \\
\hline
\end{tabular}

Values are presented as means \pm SD

Abbreviations: Ave. Average, M Male, F Female, F/u Follow-up, ROM range of motion, G-S grip strength, Q-DASH Quick Disabilities of the Arm, Shoulder, and Hand

was full, and the grip strength ratio was $79.2 \%$. The QDASH score was 0 points. CT imaging revealed that both the plate and screws clearly remained (Fig. 1).

\section{Case 2}

A 54-year-old woman had an oblique metacarpal fracture of the left ring finger as a result of a fall from standing height. Operation was performed as described in Case 1. At final follow-up visit, 6-years and 5-months post-surgery, the active ROM was full, and the grip strength ratio was $104.5 \%$. The Q-DASH score was 0 points. Both the plate and the screws were clearly visible in plain CT images.
Case 3

A 17-year-old man had an oblique metacarpal fracture of the right ring finger as a result of sliding head-first while playing baseball. Operation was performed. At final follow-up visit, 6-years and 7-months post-surgery, the active ROM was full, and the grip strength ratio was $100.7 \%$. The Q-DASH score was 0 points. Plain CT revealed that most of the implanted plate and screws remained (Fig. 2).

\section{Case 4}

An 18-year-old man had an oblique metacarpal fracture of the left ring finger as a result of a diving catch while
A

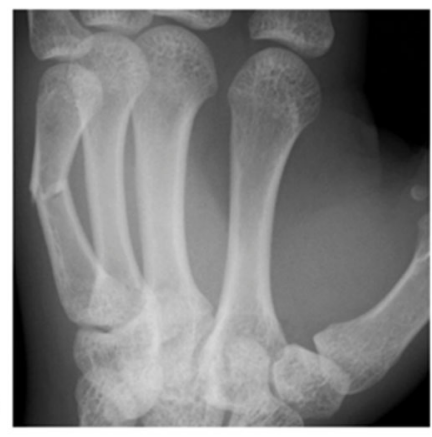

C

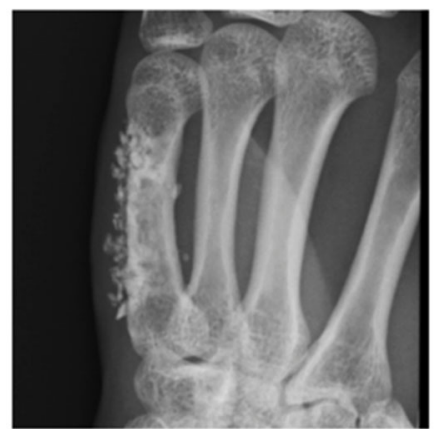

B

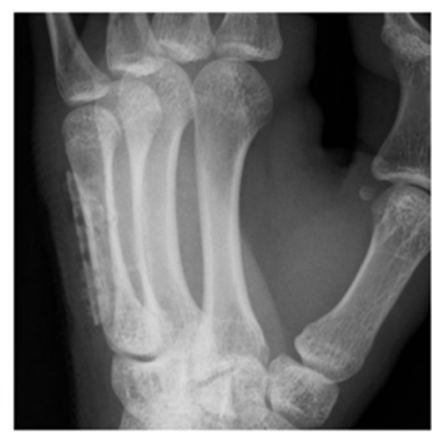

D

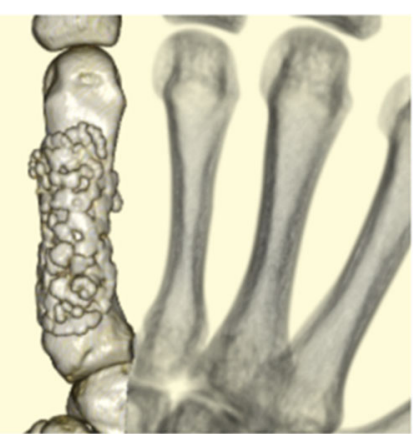

Fig. 1 Radiographic images of a repaired transverse metacarpal fracture of the left little finger in a 16-year-old male (Case 1). The preoperative radiograph (a), postoperative radiograph $(\mathbf{b})$, and final follow-up radiograph $(\mathbf{c})$, which was taken 5 years 8 months post-surgery are pictured. A final follow-up 3D-computed tomography image (d) is also shown 

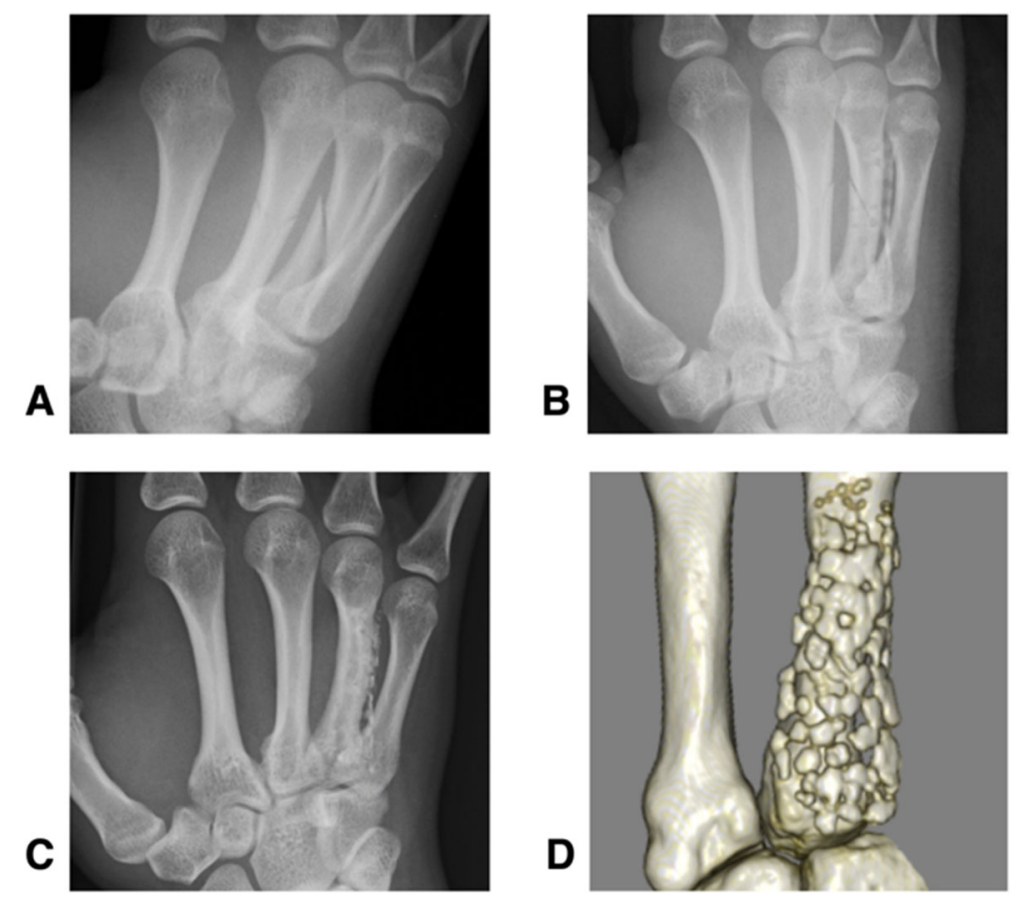

Fig. 2 Radiographic images of a 17-year-old male who had an oblique metacarpal fracture of the right ring finger (Case 3). The preoperative radiograph (a), postoperative radiograph (b), final follow-up radiograph (c) (taken 6 years 7 months post-surgery) and a final follow-up 3D-computed tomography image (d) are shown

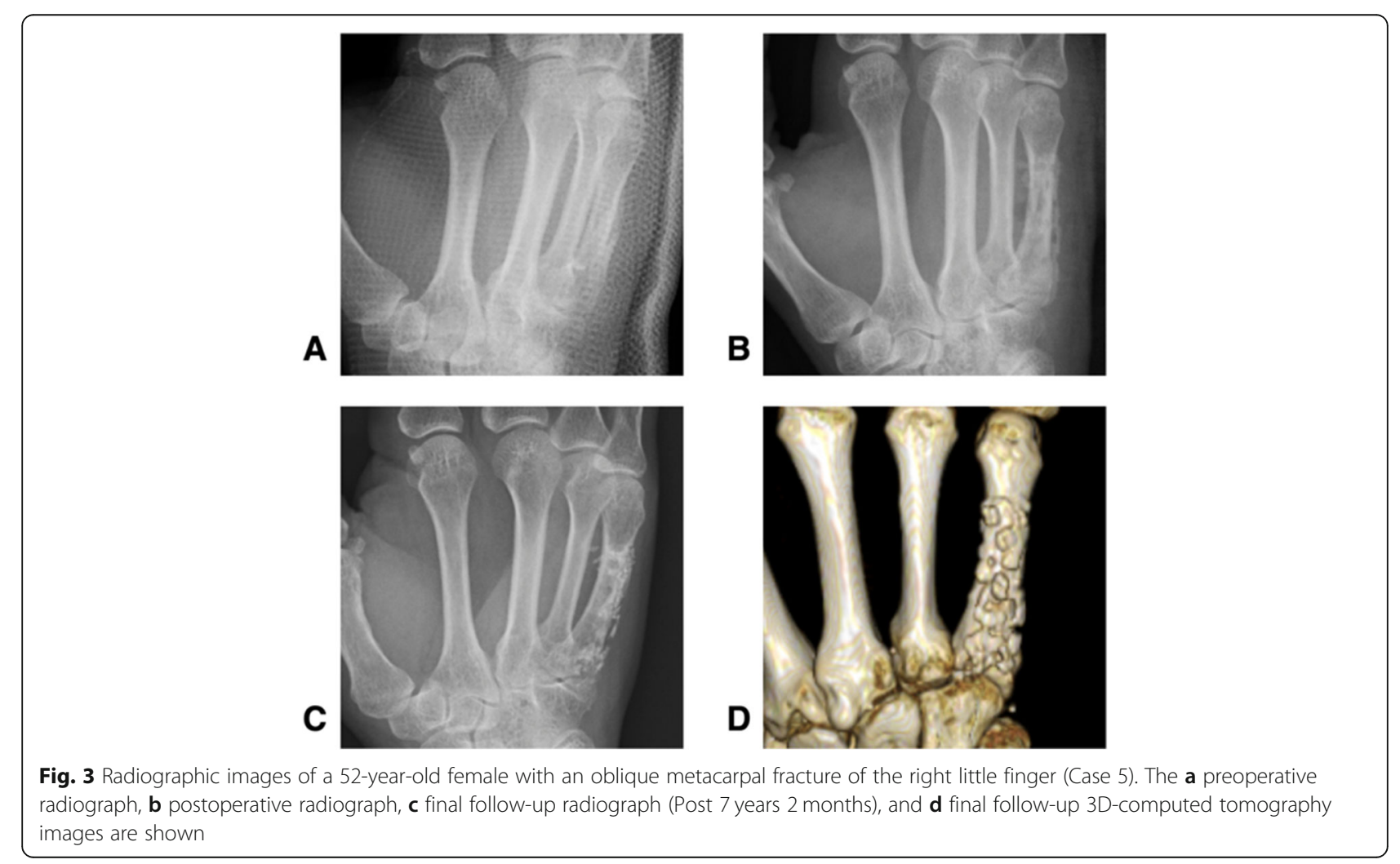


playing baseball. Operation was performed. At final follow-up visit, 6-years and 8-months post-surgery, active flexion ROM of the MCP joint was 80 degrees, therefore he could not grip completely. There were no physical findings that suggested adhesion of the extensor tendon, and there were no abnormalities observed, such as screw protrusion. The grip strength ratio was $78.5 \%$, and the Q-DASH score was 34.09 points. On plain CT images, both the plate and the screws were visible.

\section{Case 5}

A 52-year-old woman had an oblique metacarpal fracture of the right little finger as a result of a bruise while playing volleyball. Operation was performed. At final follow-up visit, 7-years and 2-months post-surgery, the active ROM was full, the grip strength ratio was $91.1 \%$, and the Q-DASH score was 0 points. On plain CT, the plate and the screws were only slightly visible (Fig. 3).

\section{Case 6}

A 20-year-old man had a comminuted metacarpal fracture of the left middle finger and oblique metacarpal fractures of the left ring and little fingers as a result of an accident that occurred at work. Operations for all injured fingers were performed. At final follow-up visit, 8- years and 5-months post-surgery, the active ROM was full; however, the grip strength ratio was $56.8 \%$, and the Q-DASH score was 34.09 points. Plain CT clearly revealed that the plates had been completely absorbed, and only screws remained slightly visible within the bone (Fig. 4).

\section{Discussion}

u-HA/PLLA composites are mainly used to treat fractures of the upper extremities $[8,17]$. Unstable metacarpal fractures are commonly treated by open reduction and internal fixation using rigid devices, such as titanium plates $[2,3]$. However, these implants are often associated with high complication rates [5, 6]. u-HA/PLLA bioabsorbable implants have been introduced as a reliable alternative to titanium plates. These absorbable implants are designed to provide several clinical advantages compared to metallic implants [8]. Firstly, mesh sheets made from $\mathrm{u}$-HA/PLLA are very thin $(0.7 \mathrm{~mm}$ thickness); therefore, the associated risk of soft tissue irritation is lower than that of titanium plates. Secondly, mesh sheets are malleable and can be placed in the best possible position to cover a fracture according to the fracture pattern. Furthermore, there are many screw holes in the mesh sheets. Therefore, surgeons have more
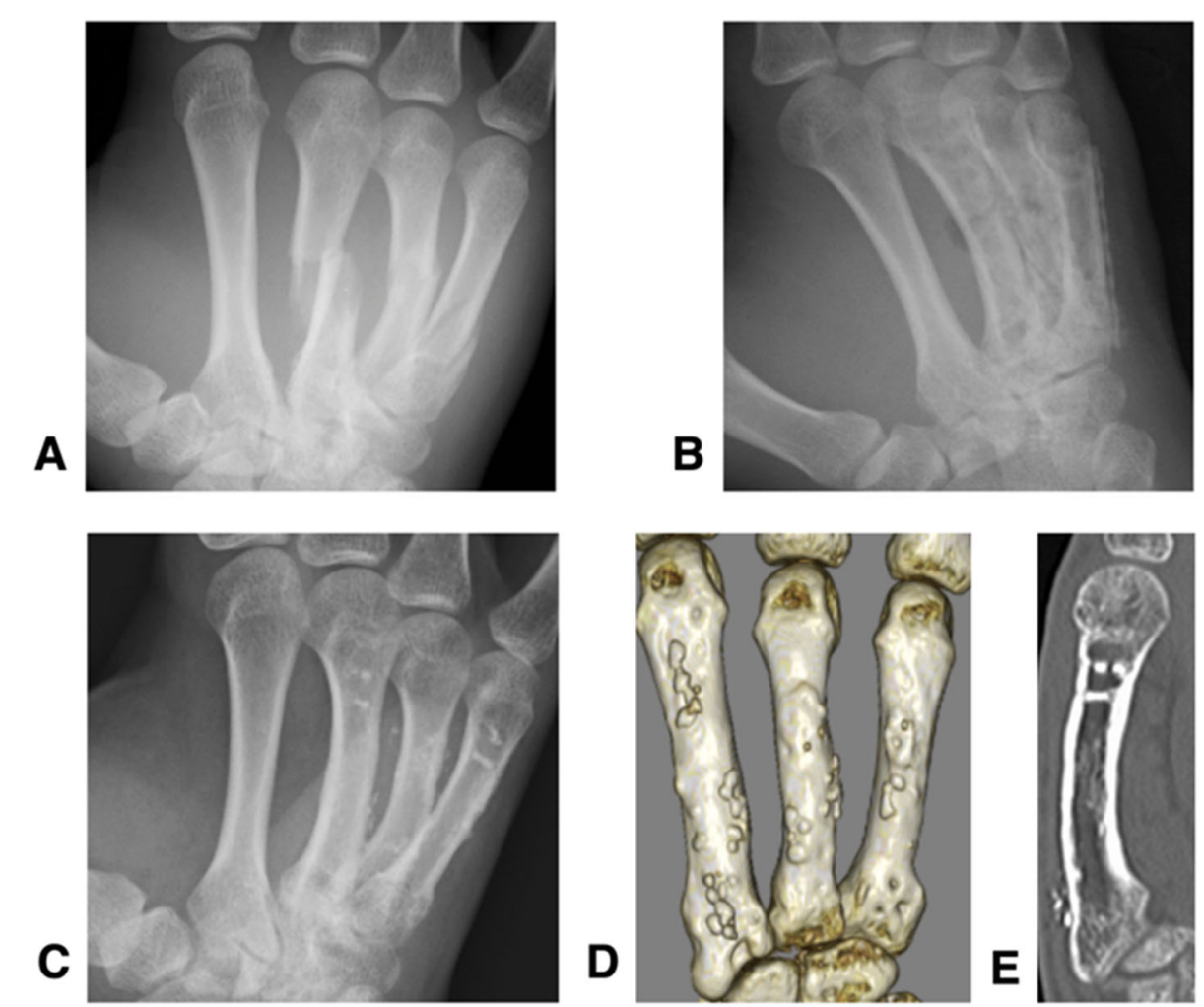

Fig. 4 Radiographic images from a 20-year-old male with a comminuted metacarpal fracture of the left middle finger and oblique metacarpal fractures of the left ring and little fingers (Case 6). The $\mathbf{a}$ preoperative radiograph, $\mathbf{b}$ postoperative radiograph, $\mathbf{c}$ final follow-up radiograph (taken 7 years 2 months post-surgery), $\mathbf{d}$ final follow-up 3D-computed tomography and $\mathbf{e}$ final follow-up plain CT images are shown 
flexibility for screw placement. The u-HA/PLLA material also serves as a good alternative for patients allergic to metal. Above all, there is no need to remove the $\mathrm{u}-\mathrm{HA} /$ PLLA bioabsorbable plates.

It has already been demonstrated that u-HA/PLLA bioabsorbable plate constructs have sufficient mechanical strength to stabilize metacarpal fractures [8]. The bending strength and stiffness of semi-tubular and onethird tubular bioabsorbable plate constructs were comparable to those of titanium plates. Further, the strengths of plates were shown to remain comparable to that of cortical bone for 6 months [11], which is more than the 3-4 months required for bone healing. In fact, good clinical results using bioabsorbable plates to repair metacarpal fractures have been reported [8]. In these studies, bioabsorbable plates were used to repair diaphyseal and proximal fractures. Fractures near the joints should be handled with care, because bioabsorbable plates have no locking system, and there is a large amount of cancellous bone in the proximal metacarpal bone near joints. Therefore, there is a possibility that screws may fall out or loosen. In addition, tapping must be performed to fix screws, and care must be taken to avoid tightening screws too strongly because the shear strength of bioabsorbable screws is weaker than that of titanium screws, and they may twist as a result of breakage between the screw shaft and head. In these cases, a rescue technique may be used to cauterize the screw stump using an electrosurgical knife to integrate it within the bioabsorbable plate. In the past, breakage of screw heads occurred in a small number of our patients; however, this complication has not recently occurred.

Delayed foreign body reactions such as inflammation and persistent swelling have been reported occasionally in the oral and maxillofacial surgical fields [13]. These are thought to be caused by mechanical irritation due to protrusion of screws that had not been degraded, and inflammatory reactions that occur throughout the process of degradation and absorption. In orthopedic literature, one study with mean followup period of 45.7 months (range, 34-61 months) showed that foreign body reactions did occur in four of nine patients that required second procedures to remove implants [18]. In this study, no implantspecific complications were reported, which indicates that operation site likely affects surgical outcomes. In oral and maxillofacial surgery, the presence of oral bacteria cannot be ignored [19]. In fact, the surgical site infection frequency of hand fractures was reported to be $1 \%$ [20], whereas that of mandibular closed fractures was reported to be $1.4-33.4 \%$ [21, $22]$. The surgery was performed as described to prevent mechanical irritation, however, other factors were unknown.
In this study, two cases yielded low Q-DASH scores. One case had limited range of motion. There were no physical findings that suggested adhesion of the extensor tendon, and there were no abnormalities observed, such as screw protrusion. Postoperative therapy was more likely to affect the observed outcome than technical problems. In another case, poor recovery of grip strength ratio was observed; however, the patient had multiple fractures which could have led to poor level of recovery.

In this study, in the case of metacarpal fractures, we found that the process of bioabsorption might be completed in about 8 years. Previous studies conducted on wrist arthritis using four-corner fusion for scapholunate advanced collapse and scaphoid nonunion advanced collapse using bioabsorbable plates indicate that it took significantly fewer years (approximately 5 years) for absorption to take place after surgery [23]. These results suggest that the speed of absorption depends on the location of surgical intervention. We speculate that the less cancellous nature of metacarpal bones may be a factor that contributes to the differences observed between metacarpal and four-corner fusion absorption rates. However, there are no studies that have demonstrated that absorption speeds of implants within the bone differ from those placed outside the bone. This study suggests that cancellous bone volume may contribute to differences in plate bioabsorption rates.

This study had three limitations. Firstly, this study assessed a case series retrospectively, and the sample size was limited to six patients. Therefore, more cases should be included in future studies. Secondly, as mentioned above, no true locking system exists, and there is a possibility that screws may have fall out or loosen. In this study, there were no cases where screws backed out. Thirdly, control group was not included in this study. In spite of these limitations, one of the strengths of this study is long-term follow-up and the results of this study suggest that the use of bioabsorbable plates is an useful option for the treatment of displaced metacarpal fractures.

\section{Conclusion}

This study demonstrates that the treatment of metacarpal fractures using bioabsorbable plates produces good outcomes, and in the case of metacarpal fractures, the process of bioabsorption might be completed in about 8 years. Bioabsorbable plates are custom-made implants and have several clinical advantages compared to metallic implants. Additionally, there is no need to remove the bioabsorbable plates, and it is possible to craft multiple original plates using only one mesh sheet; therefore, bioabsorbable plates are more cost-effective than metallic implants. The potential for bioabsorbable plates to be used in various clinical procedures is promising. 


\section{Supplementary Information}

The online version contains supplementary material available at https://doi. org/10.1186/s12891-020-03841-x.

Additional file 1. Crafting bioabsorbable plates for fixation of metacarpal fractures.

\section{Abbreviations}

u-HA/PLLA: Unsintered hydroxyapatite and poly-L-lactate composites; QDASH: Quick-Disabilities of the Arm, Shoulder, and Hand; CT: Computed tomography

\section{Acknowledgments}

The authors would like to thank Editage (www.editage.jp) for editing and reviewing the manuscript.

\section{Authors' contributions}

$Y Z$ and $A S$ had the major role in creating the plan, interpreting data, and formulating the manuscript. $Y Z, T T, Y Y, K M$, and $A S$ contributed in data collection and planning. The authors would also like to thank Editage (www. editage.jp) for editing and reviewing the manuscript. All authors read and approved the final manuscript.

\section{Funding}

The authors received no financial support for the research, authorship, and/ or publication of this article.

\section{Availability of data and materials}

The datasets used and/or analyzed during the current study are available from the corresponding author on reasonable request.

\section{Ethics approval and consent to participate}

Ethical approval was obtained from the Institutional Review Board (IRB) (2020-021) of the University of Occupational and Environmental Health Japan. Study participants provided written informed consent for participation and the use of their data in the study.

\section{Consent for publication}

The study participants provided written informed consents for participation and the use of their clinical data in this study. The written informed consents for publication of clinical details (the text and any pictures or video) were obtained from the patients' relatives and treated confidentially.

\section{Competing interests}

The authors declare no potential conflicts of interest with respect to the research, authorship, and/or publication of this article.

Received: 4 June 2020 Accepted: 26 November 2020

Published online: 07 December 2020

\section{References}

1. Debnath UK, Nassab RS, Oni JA, Davis TR. A prospective study of the treatment of fractures of the little finger metacarpal shaft with a short hand cast. J Hand Surg Br. 2004:29:214-7. https://doi.org/10.1016/J.JHSB.2004.02.020

2. Curtis BD, Fajolu O, Ruff ME, Litsky AS. Fixation of metacarpal shaft fractures: biomechanical comparison of intramedullary nail crossed K-wires and platescrew constructs. Orthop Surg. 2015;7:256-60. https://doi.org/10.1111/os. 12195.

3. Dreyfuss D, Allon R, Izacson N, Hutt D. A comparison of locking plates and intramedullary pinning for fixation of metacarpal shaft fractures. Hand. 2019; 14:27-33. https://doi.org/10.1177/1558944718798854

4. Christensen TJ, Samant SA, Shin AY. Making sense of metal allergy and hypersensitivity to metallic implants in relation to hand surgery. J Hand Surg Am. 2017:42:737-46. https://doi.org/10.1016/j.jhsa.2017.06.009.

5. Page SM, Stern PY. Complications and range of motion following plate fixation of metacarpal and phalangeal fractures. J Hand Surg Am. 1988;23: 827-32. https://doi.org/10.1016/S0363-5023(98)80157-3.

6. Fusetti C, Meyer H, Borisch N, Stern R, Papaloïzos M. Complications of plate fixation in metacarpal fractures. J Trauma. 2002;52:535-9. https://doi.org/10. 1097/00005373-200203000-00019.
7. Shikinami Y, Matsusue Y, Nakamura T. The complete process of bioresorption and bone replacement using devices made of forged composites of raw hydroxyapatite particles/poly I-lactide (F-u-HA/PLLA). Biomaterials. 2005;26: 5542-51. https://doi.org/10.1016/j.biomaterials.2005.02.016.

8. Sakai A, Oshige T, Zenke Y, Menuki K, Murai T, Nakamura T. Mechanical comparison of novel bioabsorbable plates with titanium plates and smallseries clinical comparisons for metacarpal fractures. J Bone Joint Surg Am. 2012:94:1597-604. https://doi.org/10.2106/JBJS.K.00008.

9. Singh V, Kshirsagar R, Halli R, Sane V, Chhabaria G, Ramanojam S, et al. Evaluation of bioresorbable plates in condylar fracture fixation: a case series. Int J Oral Maxillofac Surg. 2013;42:1503-5. https://doi.org/10.1016/j.ijom. 2013.06.008

10. Furukawa $T$, Matsusue $Y$, Yasunaga $T$, Shikinami $Y$, Okuno M, Nakamura T. Biodegradation behavior of ultra-high-strength hydroxyapatite/poly ( $L$ lactide) composite rods for internal fixation of bone fractures. Biomaterials. 2000;21:889-98. https://doi.org/10.1016/S0142-9612(99)00232-X.

11. Furukawa K, Sakai A, Menuki K, Oshige T, Zenke Y, Nakamura T. Posttraumatic malunion of the distal radial intra-articular fractures treated with autologous costal osteochondral grafts and bioabsorbable plates. Tech Hand Up Extrem Surg. 2014;18:15-9. https://doi.org/10.1097/BTH. 0000000000000020

12. Sukegawa S, Kanno T, Kawai H, Shibata A, Takahashi Y, Nagatsuka H, et al. Long-term bioresorption of bone fixation devices made from composites of unsintered hydroxyapatite particles and poly-L-lactide. J Hard Tissue Biol. 2015;24:219-24. https://doi.org/10.2485/jhtb.24.219.

13. Bergsma EJ, Rozema FR, Bos RR, de Bruijin WC. Foreign body reactions to resorbable poly (L-lactide) bone plates and screws used for the fixation of unstable zygomatic fractures. J Oral Maxillofac Surg. 1993;51:666-70. https:// doi.org/10.1016/s0278-2391(10)80267-8.

14. Lee JH, Chang JW, Choi MS, Ahn HC. Delayed infection after a zygoma fracture fixation with absorbable plates. J Craniofac Surg. 2010;21:2018-9. https://doi.org/10.1097/SCS.0b013e3181f5387c.

15. Park $\mathrm{CH}$, Kim HS, Lee JH, Hong SM, Ko YG, Lee OJ. Resorbable skeletal fixation systems for treating maxillofacial bone fractures. Arch Otolaryngol Head Neck Surg. 2011;137:125-9. https://doi.org/10.1001/archoto.2010.241.

16. Kennedy CA, Beaton DE, Solway S, McConnell S, Bombardier C. Disabilities of the arm, shoulder and hand (DASH), the DASH and quick DASH outcome measure User's manual. 3rd ed. Toronto: Institute for Work \& Health; 2011.

17. Hughes TB. Bioabsorbable implants in the treatment of hand fractures: an update. Clin Orthop Relat Res. 2006;445:169-74. https://doi.org/10.1097/01. blo.0000205884.81328.cc.

18. Givissis PK, Stavridis SI, Papagelopoulos PJ, Antonarakos PD, Christodoulou AG. Delayed foreign-body reaction to absorbable implants in metacarpal fracture treatment. Clin Orthop Relat Res. 2010;468:3377-83. https://doi.org/ 10.1007/s11999-010-1388-3.

19. Wade WG. The oral microbiome in health and disease. Pharmacol Res. 2013; 69:137-43. https://doi.org/10.1016/j.phrs.2012.11.006.

20. Bachoura A, Guitton TG, Smith RM, Vrahas MS, Zurakowski D, Ring D. Infirmity and injury complexity are risk factors for surgical-site infection after operative fracture care. Clin Orthop Relat Res. 2011;469:2621-30. https://doi. org/10.1007/s11999-010-1737-2.

21. Danda AK, Ravi P. Effectiveness of postoperative antibiotics in orthognathic surgery: a meta-analysis. J Oral Maxillofac Surg. 2011;69:2650-6. https://doi. org/10.1016/j.joms.2011.02.060.

22. Domingo F, Dale E, Gao C, Groves C, Stanley D, Maxwell RA, Waldrop JL. A single-center retrospective review of postoperative infectious complications in the surgical management of mandibular fractures: postoperative antibiotics add no benefit. J Trauma Acute Care Surg. 2016;81:1109-14. https://doi.org/10.1097/TA.0000000000001232.

23. Zenke Y, Oshige T, Menuki K, Hirasawa H, Yamanaka Y, Tajima T, Kosugi K, Sakai A. Four-corner fusion method using a bioabsorbable plate for scapholunate advanced collapse and scaphoid nonunion advanced collapse wrists: a case series study. BMC Musculoskelet Disord. 2020;21:683. https:// doi.org/10.1186/s12891-020-03709-0.

\section{Publisher's Note}

Springer Nature remains neutral with regard to jurisdictional claims in published maps and institutional affiliations. 